\title{
Mesoscale spatiotemporal variability in a complex host- parasite system influenced by intermediate host body size
}

\author{
Sara M. Rodríguez ${ }^{\text {Corresp., }}{ }^{1,2}$ ， Nelson Valdivia ${ }^{2,3}$ \\ 1 Programa de Doctorado en Biología Marina, Facultad de Ciencias, Universidad Austral de Chile, Campus Isla Teja s/n, Valdivia, Chile \\ 2 Instituto de Ciencias Marinas y Limnológicas, Facultad de Ciencias, Universidad Austral de Chile, Campus isla Teja s/n, Valdivia, Chile \\ 3 Centro FONDAP de Investigación en Dinámica de Ecosistemas Marinos de Altas Latitudes (IDEAL), Valdivia, Chile \\ Corresponding Author: Sara M. Rodríguez \\ Email address: saramrodriz@gmail.com
}

Background. Parasites are essential components of natural communities, but the factors that generate skewed distributions of parasite occurrences and abundances across host populations are not well understood. Methods. Here, we analyse at a seascape scale the spatiotemporal relationships of parasite exposure and host body-size with the proportion of infected hosts (i.e. prevalence) and aggregation of parasite burden across ca. $150 \mathrm{~km}$ of the coast and over 22 months. We predicted that the effects of parasite exposure on prevalence and aggregation are dependent on host body-sizes. We used an indirect hostparasite interaction in which migratory seagulls, sandy-shore molecrabs, and an acanthocephalan worm constitute the definitive hosts, intermediate hosts, and endoparasite, respectively. In such complex systems, increments in the abundance of definitive hosts imply increments in intermediate hosts' exposure to the parasite's dispersive stages. Results. Linear mixed-effects models showed a significant, albeit highly variable, positive relationship between seagull density and prevalence. This relationship was stronger for small (cephalothorax length $>15 \mathrm{~mm}$ ) than large molecrabs ( $<15 \mathrm{~mm}$ ). Independently of seagull density, large molecrabs carried significantly more parasites than small molecrabs. The analysis of the variance-to-mean ratio of per capita parasite burden showed no relationship between seagull density and mean parasite aggregation across host populations. However, the amount of unexplained variability in aggregation was strikingly higher in large that small intermediate hosts. This unexplained variability was driven by a decrease in the mean-variance scaling in heavily infected large molecrabs. Conclusions. These results show complex interdependencies between extrinsic and intrinsic population attributes on the structure of host-parasite interactions. We suggest that parasite accumulation-a characteristic of indirect host-parasite interactions-and subsequent increasing mortality rates over ontogeny underpin size-dependent hostparasite dynamics. 
1 Mesoscale spatiotemporal variability in a complex host-parasite system influenced by

2 intermediate host body size

3

4 Sara M. Rodríguez ${ }^{1,2}$ \& Nelson Valdivia ${ }^{2,3}$

5

6 1Programa de Doctorado en Biología Marina, Facultad de Ciencias, Universidad Austral de

7 Chile, campus Isla Teja s/n, Valdivia, Chile.

8 2Instituto de Ciencias Marinas y Limnológicas, Facultad de Ciencias, Universidad Austral de

9 Chile, canpus Isla Teja s/n, Valdivia, Chile.

$10{ }^{3}$ Centro FONDAP de Investigación en Dinámica de Ecosistemas Marinos de Altas Latitudes

11 (IDEAL).

12

13 Corresponding Author:

14 Sara M. Rodríguez

15 Email addresses: saramrodriz@gmail.com 


\section{Abstract}

19 Background. Parasites are essential components of natural communities, but the factors that 20 generate skewed distributions of parasite occurrences and abundances across host populations 21 are not well understood.

22 Methods. Here, we analyse at a seascape scale the spatiotemporal relationships of parasite 23 exposure and host body-size with the proportion of infected hosts (i.e. prevalence) and 24 aggregation of parasite burden across ca. $150 \mathrm{~km}$ of the coast and over 22 months. We predicted 25 that the effects of parasite exposure on prevalence and aggregation are dependent on host body26 sizes. We used an indirect host-parasite interaction in which migratory seagulls, sandy-shore 27 molecrabs, and an acanthocephalan worm constitute the definitive hosts, intermediate hosts, and 28 endoparasite, respectively. In such complex systems, increments in the abundance of definitive 29 hosts imply increments in intermediate hosts' exposure to the parasite's dispersive stages.

30 Results. Linear mixed-effects models showed a significant, albeit highly variable, positive 31 relationship between seagull density and prevalence. This relationship was stronger for small

32 (cephalothorax length $>15 \mathrm{~mm}$ ) than large molecrabs $(<15 \mathrm{~mm})$. Independently of seagull 33 density, large molecrabs carried significantly more parasites than small molecrabs. The analysis 34 of the variance-to-mean ratio of per capita parasite burden showed no relationship between 35 seagull density and mean parasite aggregation across host populations. However, the amount of unexplained variability in aggregation was strikingly higher in large that small intermediate

37 hosts. This unexplained variability was driven by a decrease in the mean-variance scaling in 38 heavily infected large molecrabs.

39 Conclusions. These results show complex interdependencies between extrinsic and intrinsic 40 population attributes on the structure of host-parasite interactions. We suggest that parasite 
41 accumulation - a characteristic of indirect host-parasite interactions - and subsequent increasing

42 mortality rates over ontogeny underpin size-dependent host-parasite dynamics. 


\section{Introduction}

45

46

47

48

49

Parasites commonly show aggregated distributions across host populations. The degree of parasite aggregation - i.e., few hosts concentrate most of the parasites — can have consequences for the stability of parasite-host interactions (Wilson et al., 2001). For example, seminal theoretical work predicts that parasite aggregation stabilises host-parasite dynamics (Anderson \& May, 1978; May \& Anderson, 1978). However, extreme aggregation in host populations with low prevalence, such that a very small proportion of hosts carry a high parasite burden, might reduce the ability of the parasite to regulate the host population (Anderson \& May, 1978). Variations in "extrinsic" factors such as exposure to infective stages of parasites (hereafter referred to as "parasite exposure") can generate parasite aggregation across hosts (McCoy et al., 2016). However, "intrinsic" host-population factors, such as age and body-size structure, can significantly influence the links between variation in parasite exposure and aggregation (Anderson \& May, 1978). Determining the links of these extrinsic and intrinsic factors with patterns of prevalence and aggregation across host populations will improve our understanding of complex host-parasite dynamics (Shaw, Grenfell \& Dobson, 1998; Wilson et al., 2001; Morand \& Krasnov, 2008).

Variations in parasite exposure can affect infection rates and thus parasite aggregation across host populations. Assuming a certain, basal level of parasite aggregation (Wilson et al., 2001), an increase in parasite exposure will lead to an increase in the proportion of infected hosts (i.e. prevalence) and the parasite burden of the already-infected individual; this is because infection increases host susceptibility to subsequent infections when there is no further increase in host's immunity (Wilson et al., 2001). For example, the Pacific chorus frog Pseudacris regilla (Baird \& Girard, 1852) shows increased susceptibility to the trematode Ribeiroa ondatrae Looss, 
671907 after being infected, because the previous infection impairs hosts' immunological system

68 (Johnson \& Hoverman, 2014). Therefore, it can be hypothesised that increased parasite exposure

69 will increase the infection rate of already-infected hosts, increasing parasite burden and therefore

70 the aggregation across the population.

71 The effect of parasite exposure on aggregation can depend on host size structure.

72 Assuming that body size is correlated with host age (Ebert, 1999), it can be suggested that small

73 hosts have been exposed for a shorter time to parasite infection than larger conspecifics (Muñoz

74 \& George-Nascimento, 2008) - this in turn should result in smaller parasite burdens in the

75 former than the latter (Grutter \& Poulin, 1998; Poulin, 2013). For example, subpopulations of

76 fish composed by larger individual have a higher prevalence and per capita parasite burden than

77 subpopulation composed by smaller individuals (Lo, Morand \& Galzin, 1998; Poulin, 2000;

78 Muñoz, Valdebenito \& George-Nascimento, 2002). Since infection is positively related with host

79 susceptibility (e.g. Johnson \& Hoverman, 2014), then it can be suggested that larger individuals

80 will have larger infections rates than smaller individuals (see Muñoz, Valdebenito \& George-

81 Nascimento, 2002; Muñoz \& George-Nascimento, 2008 for an example in fish hosts). In

82 complex parasite-host interactions, intermediate hosts are usually unable to expel the parasites

83 and thus they accumulate parasites over the lifetime (Muñoz \& George-Nascimento, 2008;

84 Campião et al., 2015). In addition, the probability of mortality can be larger for heavily infected

85 hosts, leading to a decrease in prevalence and aggregation over ontogeny (Rousset et al., 1996;

86 Duerr et al., 2003). We can expect that in such complex systems, therefore, parasite exposure

87 should have differential effects on the parasitosis of small- and large-sized intermediate hosts.

Migratory seagulls and their parasites constitute a model system to investigate how

89 parasite exposure and intermediate host size-structure relate with prevalence and aggregation. 
90 Migratory Charadriiformes are usually involved in indirect parasite-host interactions, in which

91 the birds are the definitive host and there is at least one intermediate host, usually invertebrates

92 that accumulate parasites over their ontogeny (e.g. Rodríguez, D’Elía \& Valdivia, 2016). In these

93 interactions, parasite infective stages are trophically transmitted between definitive and

94 intermediate hosts, so that variations in the abundance of the former imply significant variations

95 in parasite exposure of the latter (Latham \& Poulin, 2003; Smith, 2007). For example, local

96 increments in the abundance of migratory birds have been linked to increases in the prevalence

97 of infectious diseases in intermediate hosts (Altizer, Bartel \& Han, 2011; McCoy et al., 2016). In

98 addition, increases in seagull abundances can be followed by concomitant increments in per

99 capita parasite loads in the intermediate host populations (Latham \& Poulin, 2003; Smith, 2007).

100 Accordingly, it can be expected that increments in the abundance of migratory seagulls should

101 result in an increase in parasite exposure. If increasing exposure positively affects the mean

102 infection rate, then the concomitant increase in the spatial variance in parasite infection can

103 increase parasite prevalence and aggregation across intermediate host populations. Migratory

104 Charadriiform species are under severe threats worldwide, owing to human-induced habitat

105 destruction, hunting, and climate change-related impacts on migratory timing, among other

106 factors (Munro, 2017). Understanding how migratory Charadriiformes take part in complex host-

107 parasite systems can have therefore important implications for both, fundamental and applied 108 ecology.

109 In this study we test the hypothesis that, if the variability in parasite exposure and host

110 body size generate intra-population variability in host infection rates, both factors

111 interdependently influence prevalence and aggregation across host populations. We predicted

112 that increases in migratory seagull densities should be linked to increases in parasite prevalence 
113 and aggregation in intermediate large-, but not small-sized, intermediate hosts. An indirect host-

114 parasite interaction, composed by migratory seagulls (definitive hosts), molecrabs (intermediate

115 hosts), and an acanthocephalan worm (parasite), was analysed. In this complex system, infected

116 seagulls release the infective stage of Profilicollis altmani Meyer, 1931 in their faeces. These

117 faeces are then ingested by the molecrab Emerita analoga Stimpson, 1857, and the cycle is

118 completed after predation on molecrabs by the seagulls Larus dominicanus (Lichtenstein, 1823),

119 Chroicocephalus maculipennis Lichtenstein, 1823, Leucopheus modestus (Tschudi, 1843), and

120 Leucopheus pipixcan (Wagler, 1831; Rodríguez, D’Elía \& Valdivia, 2016). 


\section{Materials and methods}

123 This study complies with the law No 19.473 of Servicio Agrícola y Ganadero of Chile,

124 which permits observational studies on any open access coastal area. We sampled four sandy

125 beaches located in the central-southern Chilean shore. The sites were Cheuque, Curiñanco,

126 Calfuco, and Chaihuín, and spanned ca. $150 \mathrm{~km}$ of the southeast Pacific shore (Fig. 1). Three of

127 the four seagulls analysed, namely C. maculipennis, L. modestus and L. pipixcan, use these

128 shores as feeding habitats during the austral summer. Larus dominicanus can be observed in the

129 area throughout the year. These populations display large proportions of individuals infected

130 with P. altmani. On average, the individuals of the four species show comparatively large

131 numbers of $P$. altmani parasites in the intestine (see Table 1 in Rodríguez, D'Elía \& Valdivia,

132 2016). Previous records studies have described Profilicollis larvae in intestines of other

133 vertebrate hosts, such as sea otters (Hennessy \& Morejohn, 1977; Margolis et al., 1997; Mayer,

134 Dailey \& Miller, 2003). However, no adult parasites have been recorded in these hosts (Mayer,

135 Dailey \& Miller, 2003), so the probability that sea otters encompass an alternative vector of

136 infection is sill low.

137 Densities of seagulls and E. analoga were quantified trimonthly between January 2014

138 and October 2015 (i.e. 22 months). This sampling period allowed us to analyse almost two full

139 seasonal cycles of seagull migrations. In each bird census, each sandy beach was sampled in full

140 during low tide — samplers walked parallel on effluent line to avoid disturbing the seagulls. A

141 prismatic lens, with a spotting scope between 20 and 60x, was used to quantify the number of

142 individuals of the four seagull species (Navedo et al., 2015). The length of each beach was

143 determined using a GPS and the Google Earth freeware software. The abundance of seagulls was

144 expressed as the kilometric abundance index (ind $\mathrm{km}^{-1}$ ). Additionally, we quantified the number 
145 of people, dogs, and motorised vehicles (i.e. "visitors") in each site and sample time as a

146 potential factor influencing bird abundance. Preliminary regression analyses revealed no

147 significant relationship between the total number of visitors and bird abundance across sites and

148 over time $\left(\mathrm{R}^{2}=0.002 ; \mathrm{P}>0.05\right.$. Fig. $\mathrm{S} 1$ in the Supplementary Material).

149 To survey the density of molecrabs, in each site and sampling time we deployed four

150 transects randomly and perpendicularly to the shoreline. In each transect, we placed four

151 sampling stations located ca. $2 \mathrm{~m}$ apart from each other from the effluent line to the swash line.

152 Plastic corers $\left(0.03 \mathrm{~m}^{-2}\right)$ were buried to a depth of $20 \mathrm{~cm}$ (equating a volume of $\left.0.006 \mathrm{~m}^{-3}\right)$ and

153 the sand was sieved through a $1-\mathrm{mm}$ mesh sieve. Cores were combined into transects in order to

154 integrate all molecrab sizes in each sampling unit. Molecrabs were transferred to the laboratory

155 for parasite identification and sorting under binocular microscope. In the laboratory,

156 cephalothorax length $(\mathrm{mm})$ of each individual was recorded and then they were dissected in

157 order to extract the $P$. altmani cystacanths (i.e. larval stage) from the haemocoele. The host

158 population was composed by two subgroups of body sizes, one ranging from 0.65 to $15 \mathrm{~mm}$ and

159 a second group ranging from 15 to $32 \mathrm{~mm}$ (Fig. 2A). For brevity, the former and the latter will be

160 referred to as "small" and "large" hosts, respectively.

161 For each size group, site, and sampling time, prevalence and parasite burden were

162 separately estimated as the proportion of infected hosts and the per capita number of parasites,

163 respectively (Bush et al., 1997). Parasite aggregation was estimated in two ways, as the variance-

164 to-mean ratio and the scalar exponent of Taylor's power law (Taylor, 1961). The variance-to-

165 mean ratio was estimated as the quotient between the variance $\left(s^{2}\right)$ and mean $(m)$ of the per

166 capita parasite burden. This ratio varies from zero (indicating that parasites are uniformly

167 distributed among hosts) through one (indicating a random distribution of parasites), to a 
168 maximum bounded by the number of parasites in the sample (indicating an aggregated

169 distribution of parasites; reviewed in Wilson et al., 2001). The scalar exponent $b$ of Taylor's

170 power law was estimated from $s^{2}=a m^{b}$ (Taylor, 1961); where $a$ is the variance when $m=1$ and

$171 b$ is the mean-variance scalar exponent. The $b$ parameter was estimated as the slope of the natural

$172 \log -\log$ regression between $s^{2}$ and $m$ (Figs. S2 and S3 in the supplementary material). The scalar

173 exponent varies from zero (indicating a uniform distribution of parasites) through one (for a

174 random, Poisson, distribution of parasite burden), to infinity (highly aggregated distribution of

175 parasite counts). Since the intercept ( $a$ ) of this regression can vary significantly from zero with

176 small $m$ values, we took into account the former by estimating $b$ at a standard mean of $\log _{10} m=$

177 1. This estimator is called $I_{10}$ and is useful to disentangle the patterns of aggregation from those

178 of mean parasite load (Lester, 2012; Lester \& McVinish, 2016). We estimated bias-corrected

179 confidence intervals for each site after 1000 bootstrapped estimations of $I_{10}$. To further assess the

180 relationship between mean parasite load and $b$, the fits were repeated for two subpopulations of

$181 m=[0.9,1.59]$ and $[1.6,6.1]$. Prevalence and aggregation were estimated as attributes of each

182 site and sampling time, over transects within each site. These estimations were conducted

183 separately for each size group. The $b$ and $I_{10}$ indexes were estimated as attributes of each site.

184

185 Statistical Analyses

186 The prediction of size-dependent relationships of parasite prevalence and aggregation

187 with seagull density was tested by means of linear mixed-effects models (LMM). In these

188 models, molecrab body size group and bird density were fixed and crossed variables, and

189 parasite prevalence and aggregation (variance-to-mean ratio) were the dependent variables. Site

190 and sampling time (nested in site) were included in the models as random factors. For each 
191 LMM model, we estimated pseudo-R² according to Nakagawa \& Schielzeth (2013) and Johnson

192 (2014). Two types of pseudo- $\mathrm{R}^{2}$ were calculated for each model: the marginal $\mathrm{R}^{2}$, which

193 represents the variance explained by the fixed factors, and the conditional $\mathrm{R}^{2}$, which represents

194 the variance explained by both, fixed and random factors. The models were fit through Restricted

195 Maximum Likelihood (REML). The degrees of freedom of each fixed effect term (bird density,

196 molecrab size class, and interaction) were estimated through the Satterthwaite approximation,

197 and then hypothesis test was done on the basis of conditional t-tests (Pinheiro \& Bates, 2004).

198 The treatment contrast was used to estimate effect coefficients. Standardised residual-vs.-fitted

199 values plots were used to check homogeneity of variances in LMMs. Variance-to-mean ratio data

200 were $\log _{10}$-transformed to homogenise the variances between both size groups (see Results). The

201 visual analysis of residuals suggested that a Gaussian model was the most appropriate for both,

202 prevalence and $\log _{10}$ variance-to-mean ratio. Autocorrelation functions were used to check the

203 temporal autocorrelation of residuals.

204 In order to determine if the potential relationships of bird density with parasite prevalence

205 and aggregation were lagged over time (for example, the increase in bird density would result in

206 an increase of parasitosis three months later), we computed cross-correlation functions (CCF)

207 between bird density (x) and prevalence (y) and between the former and the variance-to-mean

208 ratio (y) — we additionally cross-correlated bird and molecrab abundances. All statistical analyses

209 were conducted in R 3.3.0 (R Core Team, 2016). Linear mixed-effects models, pseudo- $\mathrm{R}^{2}$, and

210 CCF were computed with the lme4, MuMIn, and stats libraries, respectively (Bates et al., 2015;

211 Bartón, 2016; R Core Team, 2016).

212 


\section{Results}

215 A total of 1,780 individuals of E. analoga were captured throughout the study. Molecrab

216 cephalothorax length varied from 0.65 to $32.1 \mathrm{~mm}$, with two modes located at 11.6 and $23.7 \mathrm{~mm}$

217 respectively (Fig. 2A). Parasite burden - i.e. the per capita number of parasites — ranged between

218 zero and 22 ind. per molecrab (Fig. 2B). In addition, parasite burden tended to increase with

219 increasing molecrab' cephalothorax length (Fig. 2B; Table 1).

220 Seagull abundance (i.e. kilometric abundance index) varied between $11 \mathrm{ind} \mathrm{km}^{-1}$ in

221 winter, to 906 ind km-1 in summer and 922 ind km-1 in autumn (Fig. 3A). Molecrab density

222 ranged between 14 ind. $0.006 \mathrm{~m}^{-3}$ and 167 ind. $0.006 \mathrm{~m}^{-3}$ in summer and spring, respectively

223 (Fig. 3B). Bird and small-sized molecrab abundances showed instantaneous (i.e. no lagged)

224 correlations in Cheuque (Fig. S4 in the Supplementary Material). In addition, bird abundance

225 was correlated with both, small and large molecrabs at three-month lag in Calfuco (Fig. S4 in the

226 Supplementary Material).

227 Site-level prevalence values were $44 \pm 18 \%$ (mean \pm standard deviation) and $79 \pm 15 \%$

228 for small and large molecrabs, respectively (Fig. 4A and B). For both groups, prevalence was

229 highly variable across sites and over time, with maximum values occurring in summer 2015

230 (small molecrabs, Fig. 4A) and winter 2014 (large molecrabs, Fig. 4B). Despite these variable

231 patterns, the analysis of LMM detected a significant relationship between bird abundance and

232 prevalence (Fig. 4C, Table 2). In addition, large molecrabs showed ca. $40 \%$ higher prevalence

233 than the small molecrabs (Fig. 4C, Table 2). The slope between bird density and prevalence

234 tended to be steeper for small than large molecrabs (Fig. 4C), albeit this difference was not

235 statistically significant at alpha $=0.05$ (Table 2). The fixed factors in the model accounted for ca.

$23654 \%$ of the variability in prevalence, while the entire model accounted for ca. $76 \%$ (Table 2). 
238 time (Figs. 5A and 5B). In addition, the uncertainty was also greater in large than small hosts, 239 evidenced by the broader ranges in aggregation observed in the former (Figs. 5A and 5B). This

240 wide and size-dependent variation led to a statistically non-significant relationship of

241 aggregation with bird density and molecrab body size (Table 2). The analysis of aggregation at a

242 fixed mean parasite load of $m=1\left(I_{10}\right)$ suggested, however, that the apparent greater aggregation

243 and stochasticity in large molecrabs was due to heterogeneities in mean parasite load, as $I_{10}$

244 scores remained similar across sites (Figs. 5C and 5D). The small-sized molecrab subpopulations

245 showed $I_{10}$ scores between 1 and 2 across sites (Fig. 5C). The large molecrabs showed slightly

246 larger $I_{10}$ scores in Cheuque and Chaihuín (Fig. 5D). These results point to a general Poisson

247 distribution of parasites in the study region.

248 In addition, $b$ depended on mean parasite load, as large-sized molecrabs showed a

249 statistically significant $b=1.1(0.4)$ when $m<1.6$, but non-significant $b=0.9(0.7)$ when $m \geq 1.6$

250 (standard errors bracketed). Prevalence and aggregation (variance-to-mean ratio) did not show

251 lagged correlations with bird density or molecrab abundance across host sizes — the lack of

252 correlation of molecrab abundance with prevalence indicates that the former values are

253 comparable between sites, times, and size groups (Figs. S5-S8 in the Supplementary Material). 


\section{Discussion}

This study showed complex relationships of parasite exposure, represented by definitive

258 host abundances, with prevalence and aggregation across intermediate host population.

259 Acanthocephalan prevalence across molecrab populations was significantly related with bird

260 abundance, suggesting a link between parasitosis and parasite exposure. However, this

261 relationship was relatively inconsistent, as random effects of temporal surveys and sites

262 accounted for ca. $20 \%$ of the variation in prevalence. In addition, we observed that prevalence in

263 large $(>15 \mathrm{~mm})$ molecrabs was significantly larger than in small $(<15 \mathrm{~mm})$ molecrabs. Over

264 seasonal surveys and across sites, parasite aggregation remained relatively constant for small, but

265 highly variable and unpredictable for large molecrabs. However, these latter patterns were

266 largely driven by variations in mean parasite load, rather than actual aggregation. Moreover,

267 further analyses of Taylor's power law showed that greater mean parasite loads were associated

268 with slower increases in the load variance with the mean of large molecrabs. Below, we discuss

269 how parasite accumulation over the ontogeny and differential mortality rates across host

270 populations can influence the links among parasite exposure, intermediate-host size structure,

271 and parasitosis.

272 We observed a significant positive relationship between prevalence and body size of the

273 intermediate hosts. Similarly, the analyses indicate heavier parasite load in large individuals.

274 Parasite accumulation over time could explain these trends. The analysed host-parasite

275 interaction is characterised by the inability of hosts to expel the parasites once they are allocated

276 in the haemocoele (Latham \& Poulin, 2003). Accordingly, larger molecrabs, which have been

277 exposed for longer time to successive infections, accumulate parasites over the ontogeny. Similar

278 processes have been described for other endoparasites, like Profilicollis antarcticus 
279 Zdzitowiecki, 1985 and P. novaezelandensis Brockerhoff \& Smales, 2002, which accumulate

280 over the ontogeny of Ocipodidae and Grapsidae crabs (Latham \& Poulin, 2003). Similarity, the

281 prevalence, intensity, and taxonomic richness of a number of endoparasite groups can increase

282 during the ontogeny of fish hosts (Muñoz, Valdebenito \& George-Nascimento, 2002). Moreover,

283 body size of anuran hosts can be a strong predictor of the richness of helminthic fauna-this

284 pattern is consistent across hosts' geographic ranges and phylogenetic correlations, in addition to

285 sampling effort (Campião et al., 2015). Accordingly, parasite accumulation seems to be a

286 widespread characteristic of indirect host-parasite interactions.

287

In our study, size-dependent mortality might explain the significant decrease in the scalar coefficient of Taylor power law with increasing mean parasite load in the large-sized molecrab subpopulation. Latham \& Poulin (2002) indicate that high parasite burden of two acanthocephalan species increase the mortality rate in largest crab size-classes. Acanthocephalan species are non-lethal parasites, but they can alter host's behaviour and increase their susceptibility to predation (Latham \& Poulin, 2002; Beisel \& Médoc, 2010). For example, molecrab' burrowing velocity is negatively correlated with parasite burden (Jerez \& GeorgeNascimento, 2010). In addition, egg mortality during dispersion could also have led to the nonsignificant relationship between bird density (i.e. exposure to parasite infection) and the comparatively low levels of aggregation observed in this study. Abiotic environmental variables 297 related with emersion, such as desiccation and heat stress can affect negatively parasite' egg 298 viability (Herrman \& Poulin, 2011; Studer \& Poulin, 2012; Studer, Lamare \& Poulin, 2012). 299 Molecrab life history would offer a third explanation for the uncertainty in parasite load of large300 sized host. We observed that molecrab recruitment strongly varied across geographic locations, 301 with site-dependent peaks occurring in summer, autumn, and spring (but see Contreras, Defeo \& 
302 Jaramillo, 1999). An increase in non-infected recruits can have negative (positive) effects on

303 prevalence (aggregation) across the host population (e.g. Zambrano \& George-Nascimento,

304 2010), which might decouple the relationship between exposure and the parasitosis in the

305 intermediate host. Further field-based comparative experiments would be useful to tease apart

306 the effects of exposure, egg mortality, and recruitment timing on parasite aggregation.

307 To what degree these results could be generalised to other host-parasite systems? The life

308 cycles of almost all acanthocephalan and digenetic species, as well as some nematodes and

309 cestodes, include at least one intermediate host that accumulates parasites over time (Thomas,

310 Guégan \& Renaud, 2009). In addition, size-dependent responses of prevalence to parasite

311 exposure have been demonstrated in other complex host-parasite interactions involving

312 migratory birds and crustaceans (Latham \& Poulin, 2003; Smith, 2007; Zambrano \& George-

313 Nascimento, 2010). In the same line, parasite burden increases with body size of the toadfish

314 Aphos porosus Valenciennes, 1837, an intermediate host of cestodes, nematodes, trematodes, and

315 acantocephalans (Cortés \& Muñoz, 2008). These examples suggest that accumulation of

316 endoparasites in intermediate hosts may be a common phenomenon. Contrarily, ectoparasites,

317 which can be removed by hosts, can show different patterns of prevalence and aggregation. In

318 such systems, the smaller or younger hosts accumulate greater parasite burdens than older hosts,

319 as a likely consequence of higher susceptibility to infections of the former than the latter (McCoy

320 et al., 2016). Therefore, significant relationships between parasite exposure and prevalence, in

321 addition with size-dependent patterns of stochasticity in parasite load could be observed in other

322 complex host-parasite systems, at least those involving endoparasites that accumulate over host'

323 ontogeny. 
324 In summary, our results showed that parasitosis could be related with exogenous

325 (exposure) and endogenous (host body size) factors in a complex fashion. Parasite exposure was

326 positively related with prevalence in the intermediate host population. Prevalence and parasite

327 load were dependent of intermediate host body size, which may be explained by parasitosis-

328 related increasing mortality rates over host' ontogeny. Also, these results would be generalised to

329 other complex parasite with an intermediate host that accumulates parasite over time. These

330 results suggest that intrinsic host-population characteristic can have stronger effects on the

331 dynamic of host-parasite interactions than extrinsic factors. Overall, our study contributes to the

332 understanding of the processes that underpin the heterogeneity in parasite burden across host

333 populations.

334

335 Acknowledgements

336

337

We thank all undergraduate interns (Biología Marina; UACH) that provided invaluable

338 help during the fieldwork. Daniela López contributed with helpful suggestions and discussions

339 that improved previous versions of this manuscript. This paper belongs to $\mathrm{SMR} \mathrm{PhD}$ thesis

340 dissertation at Universidad Austral de Chile. 


\section{References}

344

345 Altizer S, Bartel R, Han BA. 2011. Animal migration and infectious disease risk. Science 331:

346 296-302.

347

348 Anderson RM, May RM. 1978. Regulation and stability of host-parasite population interactions

349 I. Regulatory processes. Journal of Animal Ecology 47: 219-247.

350

351 Beisel J, Medoc V. 2010. Bird and amphipod parasites illustrate a gradient from adaptation to 352 exaptation in complex life cycle. Ethology Ecology \& Evolution 22: 265-270.

353

354 Bartón K. 2016. Multi-Model inference. R package version 3.3.0. https://CRAN.R355 project.org/package=MuMIn.

356

357 Bates D, Mächler M, Bolker B, Walker S. 2015. Fitting Linear Mixed-Effects Models Using 358 1me4. Journal of Statistical Software 67: 1-48.

360 Bush A, Lafferty KD, Lotz J, Shostak A. 1997. Parasitology meets ecology on its own terms, 361 Margolis et al. revisited. Journal of Parasitology 83: 575-583.

362

363 Campião K, De Aquino Ribas AC, Morais DH, Da Silva RJ, Tavares LER. 2015. How many 364 parasites species a frog might have? Determinants of parasites diversity in south American 365 anurans. PLoS ONE 10: e0140577. DOI 10.1371/journal.pone.0140577. 
367 Contreras H, Defeo O, Jaramillo E. 1999. Life history of Emerita analoga (Stimpson)

368 (Anomura, Hippidae) in a sandy beach of south central Chile. Estuarine, Coastal and Shelf

369 Science 48: 101-112.

370

371 Cortés Y, Muñoz G. 2008. Eumetazoan parasite infracommunities of the toadfish Aphos porosus

372 (Valenciennes, 1837) (Actinopterygii: Batrachoidiformes) from central Chile. Revista de

373 Biología Marina y Oceanografía 43: 255-263.

374

375 Duerr HP, Dietz K, Schulz-Key H, Büttner DW, Eichner M. 2003. Density-dependent parasite

376 establishment suggests infection-associated immunosuppression as an important mechanism for

377 parasite density regulation in onchocerciasis. Transactions of the Royal Society of Tropical

378 Medicine and Hygiene 97: 242-250.

379

380

Ebert TA. 1999. Plant and Animal Populations. Methods in Demography. Academic Press, San

381

Diego, California.

382

383 Goulding TC, Cohen CS. 2014. Phylogeography of a marine acanthocephalan: lack of cryptic

384 diversity in a cosmopolitan parasite of mole crabs. Journal of Biogeography 41: 965-976.

385

386 Grutter AS, Poulin R. 1998. Intraspecific and interspecific relationships between host size and

387 the abundance of parasitic larval gnathiid isopods on coral reef fishes. Marine Ecology Progress

388 Series 164: 263-271. 
390 Hennessy SL, Morejohn VJ. 1977. Acanthocephalan parasites of the sea otter, Enhydra lutris, off 391 coastal California. California Fish and Game 63: 268-272.

392

393 Herrmann KK, Poulin R. 2011. Life cycle truncation in a trematode: Does higher temperature 394 indicate shorter host longevity? International Journal for Parasitology 41: 697-704. 395

396 Jerez R, George-Nascimento M. 2010. Asociación del parasitismo por Profilicollis bullocki 397 (Paleacanthocephala, Polymorphidae) con la conducta y la pigmentación de Emerita analoga 398 (Anomura, Hippidae) en Chile. Revista de Biología Marina y Oceanografía 45: 525-529.

399

400 Johnson PCD. 2014. Extension Nakagawa \& Schielzeth's R_GLMM² to random slopes models. 401 Methods in Ecology and Evolution 5: 44-946.

402

403 Johnson PTJ, Hoverman JT. 2014. Heterogeneous hosts: how variation in host size, behaviour 404 and immunity affects parasite aggregation. Journal of Animal Ecology 83: 1103-1112. 405 406 Latham ADM, Poulin R. 2002a. Effect of acantocephalan parasites on hiding behaviour in two 407 species of shore crabs. Journal of Helminthology 76: 323-326.

408

409 Latham ADM, Poulin R. 2002b. Field evidence of the impact of two acanthocephalan parasites 410 on the mortality of three species of New Zealand shore crabs (Brachyura). Marine Biology 141: 411 1131-1139. 
412

413 Latham ADM, Poulin R. 2003. Spatiotemporal heterogeneity in recruitment of larval parasites to

414 shore crab intermediate hosts: the influence of shorebird definitive hosts. Canadian Journal of

415 Zoology 81: 1282-1291.

416

417 Lester RJG. 2012. Overdispersion in marine fish parasites. Journal of Parasitology 98: 718-721.

418

419 Lester RJG, Mc Vinish R. 2016. Does moving up a food chain increase aggregation in parasites?.

420 Journal Royal of Society Interfase 13: 20160102. http://dx.doi.org/10.1098/rsif.2016.0102.

421

422 Lo CM, Morand S, Galzin R. 1998. Parasite diversity/host age and size relationship in three 423 coral-reef fishes from French Polynesia. International Journal for Parasitology 28: 1695-1708.

424

425 Margolis L, Groff JM, Johnson SC, McDonald TE, Kent ML, Blaylock RB. 1997. Helminth 426 parasites of sea otters (Enhydra lutris) from Prince William Sound, Alaska: comparisons with 427 other populations od sea otters and comments on the origin of their parasites. Journal of 428 Helminthology 64: 161-168.

429

430 May M, Anderson RM. 1978. Regulation and stability of host-parasite population interactions:

431 II. Destabilizing processes. Journal of Animal Ecology 47: 249-267.

432 
433 Mayer KA, Dailey MD, Miller MA. 2003. Helminth parasites of the southern sea otter Enhydra

434 lutris nereis in central California: abundance, distribution and pathology. Diseases of Aquatic

435 Organisms 53: 77-88.

436

437 McCoy KD, Dietrich M, Jaeger A, Wilkinson DA, Bastien M, Lagadec E, Boulinier T, Pascalis

438 H, Tortosa P, Le Corre M, Dellagi K, Lebarbenchon C. 2016. The role of seabirds of the Iles

439 Eparses as reservoirs and disseminators as parasites and pathogens. Acta Oecologica 72: 98-109.

440

441 Morand S, Krasnov B. 2008. Why apply ecological laws to epidemiology? Trends in

442 Parasitology 24: 304-309.

443

444 Munro M. 2017. What's killing the world's shorebirds? Nature 541: 16-20.

445

446 Muñoz G, Valdebenito V, George-Nascimento M. 2002. La dieta y la fauna de parásitos

447 metazoos del torito Bovichthys chilensis Regan 1914 (Pisces: Bovichthydae) en la costa de Chile

448 centro-sur: variaciones geográficas y ontogenéticas. Revista Chilena de Historia Natural 75 :

$449 \quad 661-671$.

450

451 Muñoz G, George-Nascimento M. 2008. The effect of Anonchocephalus chilensis Riggenbach

452 (Eucestoda: Bothriocephalidea) on infracommunity patterns in Genypterus maculatus Tschudi

453 (osteichthyes: Ophidiidae). Journal of Helminthology 82: 221-226.

454 
455 Nakagawa S, Schielzeth H. 2013. A general and simple method for obtaining $\mathrm{R}^{2}$ from

456 Generalized Linear Mixed-effects Models. Methods in Ecology and Evolution 4: 133-142.

457

458 Navedo JG, Fernández G, Fonseca J, Drever MC. 2015. A potential role of shrimp farms for the 459 conservation of Nearctic shorebird population. Estuaries and Coasts 38: 836-845.

460

461 Pinheiro JC, Bates DM. 2004. Mixed-effects models in S and S-Plus. New York: Springer. 462

463 Poulin R. 2000. Variation in the intraspecific relationship between fish length and intensity of 464 parasitic infection: biological and statistical causes. Journal of Fish Biology 56: 123-137. 465

466 Poulin R. 2013. Explaining variability in parasite aggregation levels among host samples.

467 Parasitology 140: 541-546.

468

469 R Development Core Team. 2012. R: a language and environment for statistical computing.

470

2.15.0 ed. Vienna: R Foundation for Statistical Computing.

471

472 Rodríguez SM, D’Elía G, Valdivia N. 2016. The phylogeny and life cycle of two species of

473 Profilicollis (Acanthocephala: Polymorphydae) in marine hosts off the Pacific coast of Chile.

474 Journal of Helminthology http://dx.doi.org/10.1017/S0022149X16000638.

475

476 Rousset F. 1996. Inference of parasite-induced host mortality from distributions of parasite 477 loads. Ecology 77: 2203-2211. 
478

479 Shaw DJ, Grenfell BT, Dobson AP. 1998. Pattern of macroparasite aggregation in wildlife host 480 populations. Parasitology 117: 597-610.

481

482 Smith NF. 2007. Associations between shorebird abundance and parasites in the sand crabs, 483 Emerita analoga, along the California coast. Journal of Parasitology 93: 265-273.

484

485 Studer A, Poulin R. 2012. Effects of salinity on an intertidal host-parasite system: Is the parasite 486 more sensitive than its host? Journal of Experimental Marine Biology and Ecology 412: 110487116.

488

489 Studer A, Lamare MD, Poulin R. 2012. Effects of ultraviolet radiation on the transmission 490 process of an intertidal trematode parasite. Parasitology 139: 537-546.

491

492 Taylor LR. 1961. Aggregation, variance and the mean. Nature 189: 732-735.

493

494 Thomas F, Guégan JF, Renaud F. 2009. Ecology and evolution of parasitism. Oxford University 495 Press, Oxford, UK.

496

497 Wilson K, Bjørnstad ON, Dobson AP, Merler A, Poglayen G, Randolph SE, Read AF, Skorping 498 A. 2001. Heterogeneities in macroparasite infections. Patterns and processes. In: Hudson PJ, 499 Rizzoli A, Grenfell BT, Heesterbeek H, Dobson AP, ed. The ecology of wildlife diseases. 500 Oxford: Oxford University Press, 6-44 
501

502 Zambrano D, George-Nascimento M. 2010. Parasitism by Profilicollis bullocki (Acanthocephala:

503 Polymorphidae) in Emerita analoga (Anomura, Hippidae), according to contrasting conditions of

504 abundance of definitive hosts in Chile. Revista de Biología Marina y Oceanografia 45: 277-283. 


\section{Figure legend}

507 Figure 1. Study sites. Site codes are CHEU $=$ Cheuque, CURI $=$ Curiñanco, CALF $=$ Calfuco, 508 and CHAI = Chaihuín.

509

510 Figure 2. (A) Size-structure of the molecrab Emerita analoga and (B) relationship between body 511 size $(\mathrm{mm})$ and parasite burden (number of parasites ind $\left.{ }^{-1}\right)$.

512

513 Figure 3. Mesoscale spatiotemporal patterns of (A) bird and (B) molecrab abundances during 5142014 and 2015. $\mathrm{Su}=$ summer, $\mathrm{Au}=$ autumn, $\mathrm{Wi}=$ winter, $\mathrm{Sp}=$ spring. Symbols indicate the 515 study sites.

516

517 Figure 4. Patterns of parasite prevalence in population fractions composed by (A) small and (B)

518 large hosts during 2014 and 2015. $\mathrm{Su}=$ summer, $\mathrm{Au}=$ autumn, $\mathrm{Wi}=$ winter, $\mathrm{Sp}=$ spring. (C)

519 Relationship between bird abundance and prevalence; the statistical fits between both variables is 520 shown adjusted for host body size (see coefficients in Table 2).

521

522 Figure 5. Spatial patterns of parasite aggregation estimated as (A, B) the variance-to-mean ratio 523 and $(C, D)$ the scalar coefficient of Taylor's power law for small $(A, C)$ and large $(B, D)$ 524 molecrabs. 
527 Table 1: Number of small and large crabs of $E$. analoga, number of parasites in small and large

528 molecrabs (SM and LM) and number of seagulls for each sample seasons during 2014 and 2015.

$529 \mathrm{Su}=$ Summer, $\mathrm{Au}=$ Autumm, $\mathrm{Wi}=$ Winter, $\mathrm{Sp}=$ Spring.

530

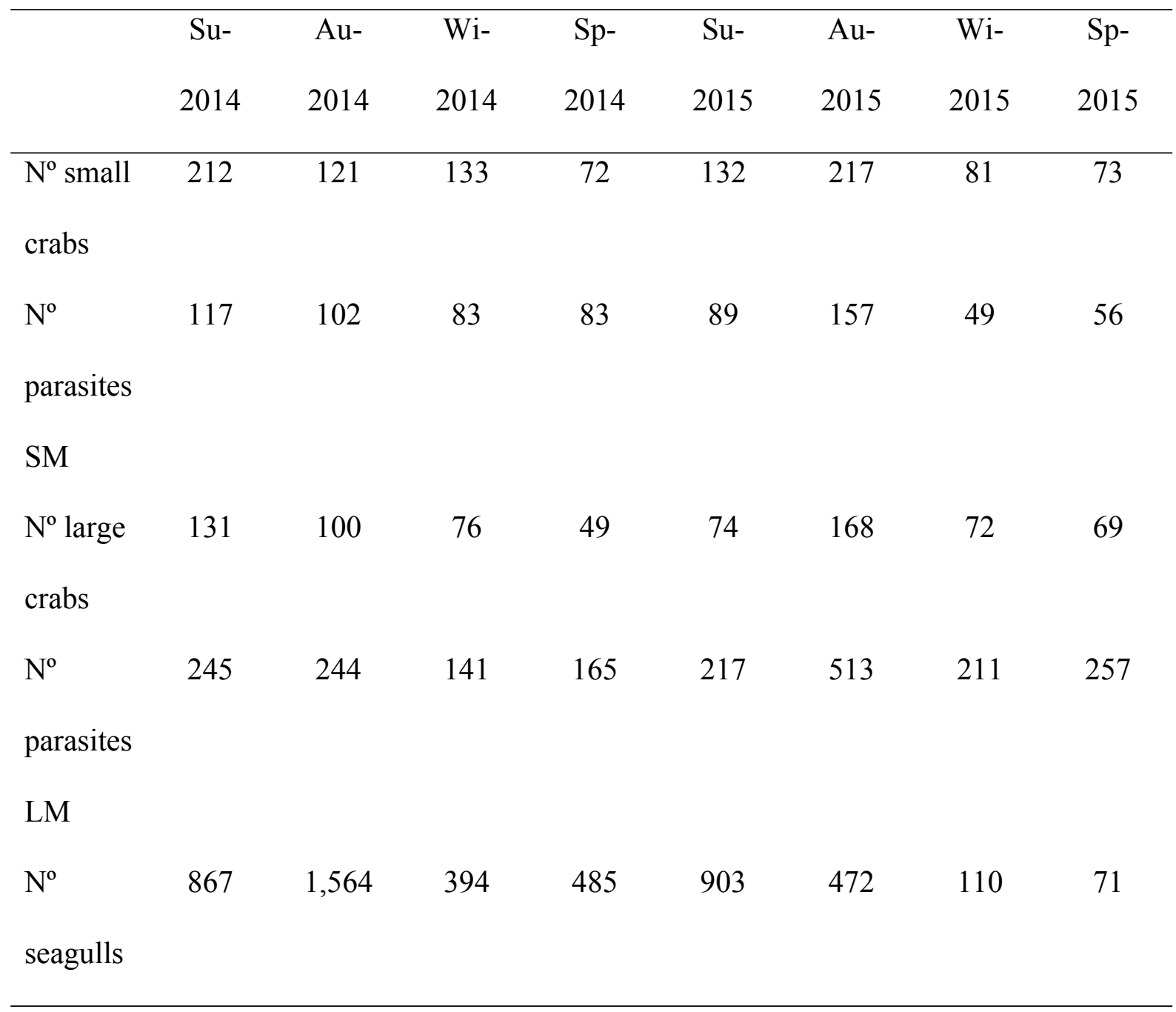


532 Table 2. Results of LMM for the relationships of parasitosis (prevalence and variance-to-mean

533 ratio of parasite burden) with bird abundance and molecrab body size. Estimate effects, their

534 standard errors (S.E.), degrees of freedom (D.F.), and t statistics are provided for each fixed

535 effect term. Degrees of freedom were estimated through Satterthwaite approximation. $R^{2} m$ and

$536 R^{2} c$ are the marginal and critical pseudo- $\mathrm{R}^{2}$, which represent the variability accounted for fixed

537 and the entire model, respectively.

538

\begin{tabular}{|c|c|c|c|c|c|c|c|c|}
\hline & Term & Estimate & S.E. & D.F. & t-value & P-value & $\mathrm{R}^{2} \mathrm{~m}$ & $\mathrm{R}^{2} \mathrm{c}$ \\
\hline \multirow[t]{5}{*}{ Prevalence } & Intercept & 0.3871 & 0.0624 & 4.54 & 6.203 & 0.002 & 0.538 & 0.757 \\
\hline & Bird density & 0.0002 & 0.0001 & 53.36 & 2.150 & 0.036 & & \\
\hline & Effect of large & & & & & & & \\
\hline & molecrabs & 0.4120 & 0.0416 & 29.39 & 9.913 & $<0.001$ & & \\
\hline & Interaction & -0.0002 & 0.0001 & 28.93 & -1.896 & 0.068 & & \\
\hline Variance-to-mean & Intercept & 0.1843 & 0.0538 & 18.32 & 3.4287 & 0.0029 & 0.138 & 0.154 \\
\hline \multirow[t]{4}{*}{ ratio $\left(\log _{10}\right)$} & Bird density & -0.0001 & 0.0002 & 58.32 & -0.7427 & 0.4607 & & \\
\hline & Effect of large & & & & & & & \\
\hline & molecrabs & 0.0726 & 0.0719 & 56.04 & 1.0096 & 0.3170 & & \\
\hline & Interaction & 0.0004 & 0.0002 & 55.98 & 1.5970 & 0.1159 & & \\
\hline
\end{tabular}

539 


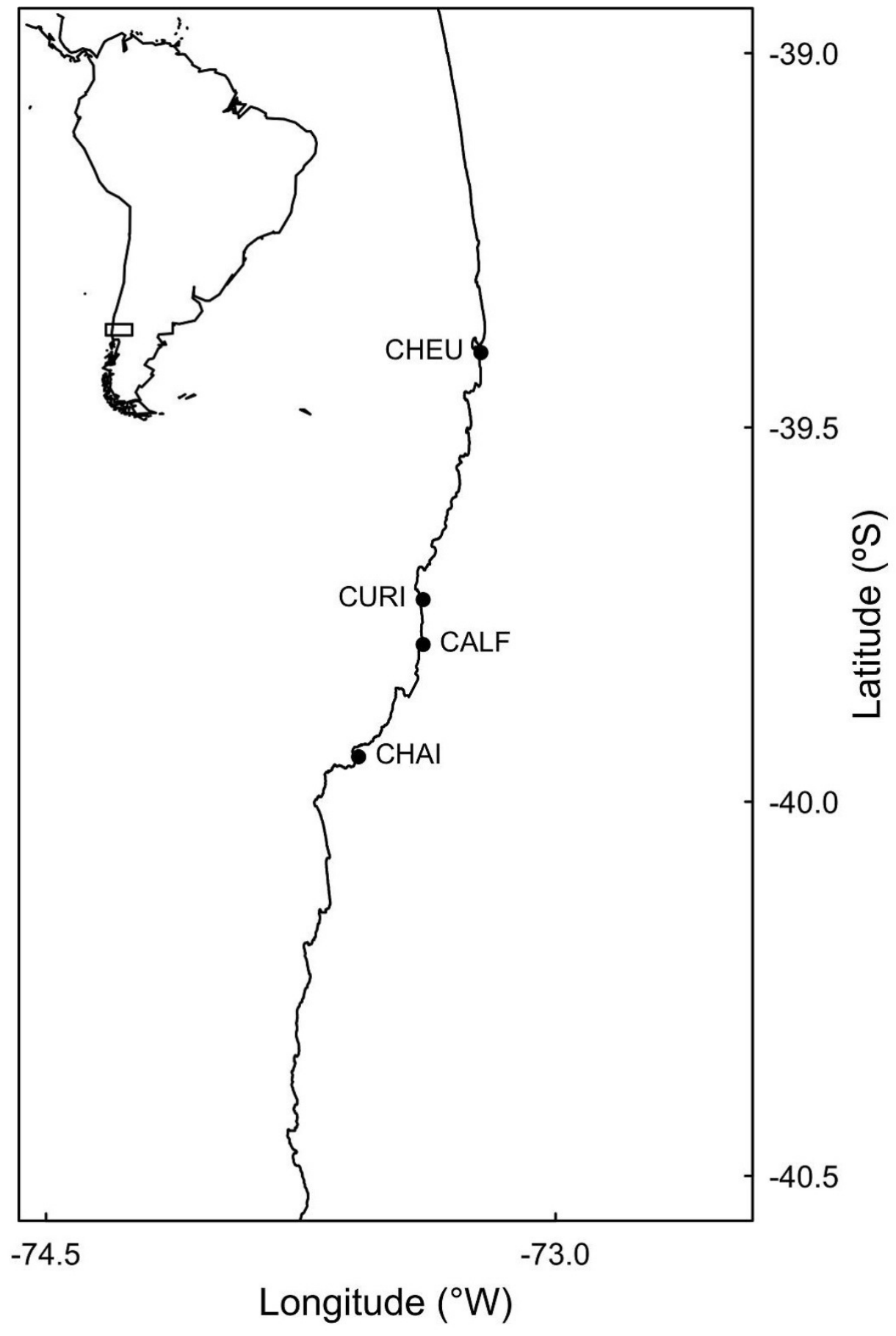

540

541 Figure 1: Rodríguez \& Valdivia

542

543

544 
A

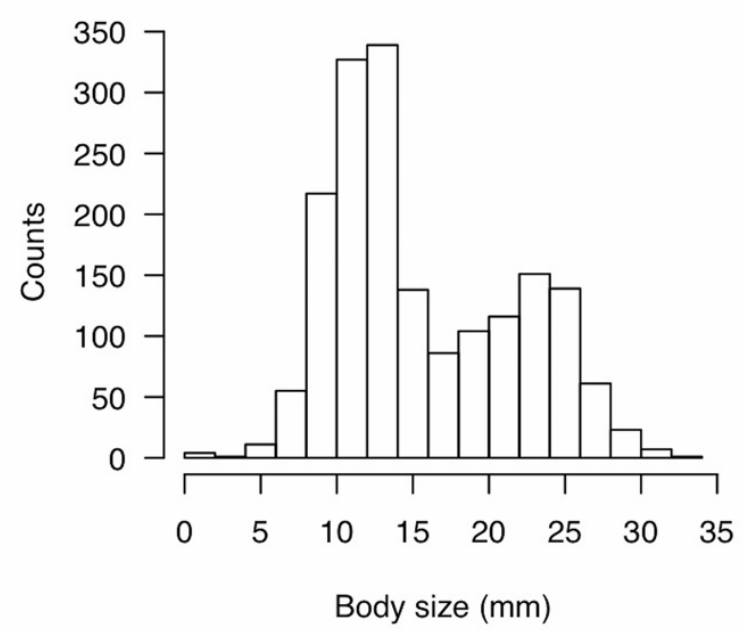

B

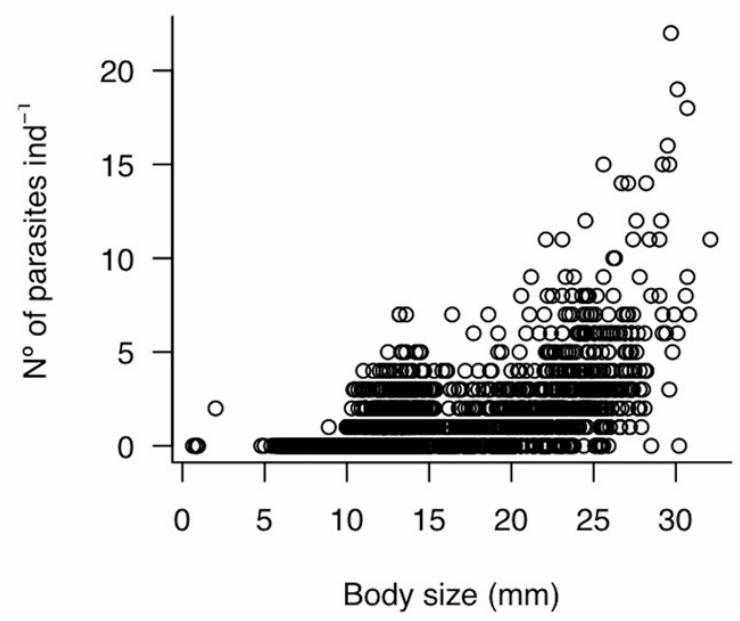

545

546 Figure 2: Rodríguez \& Valdivia. 
A

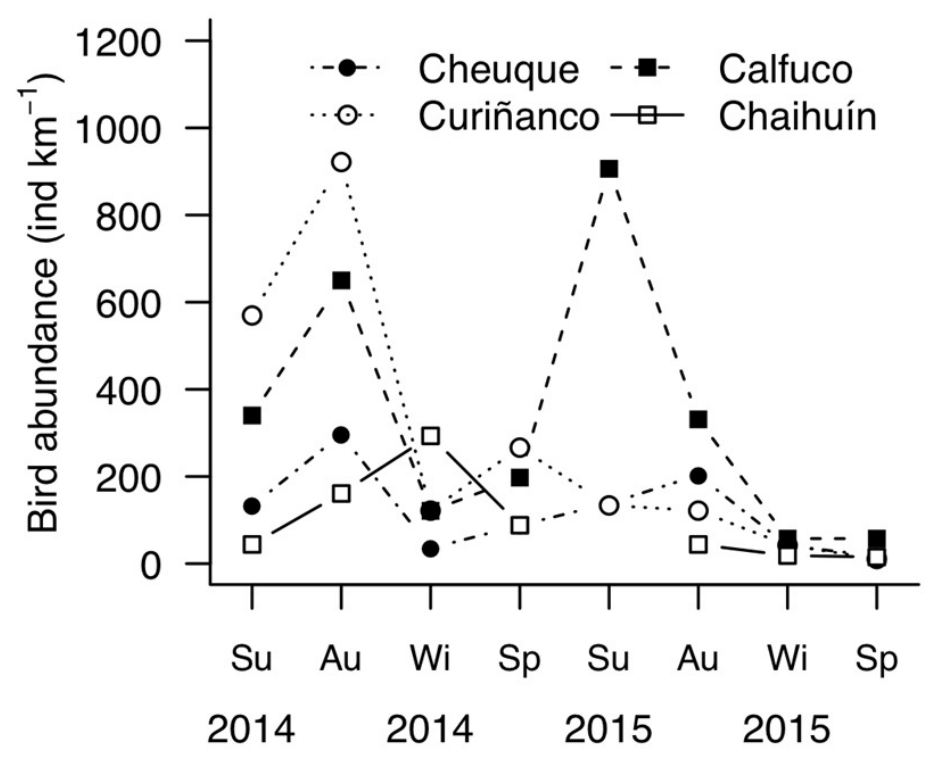

B

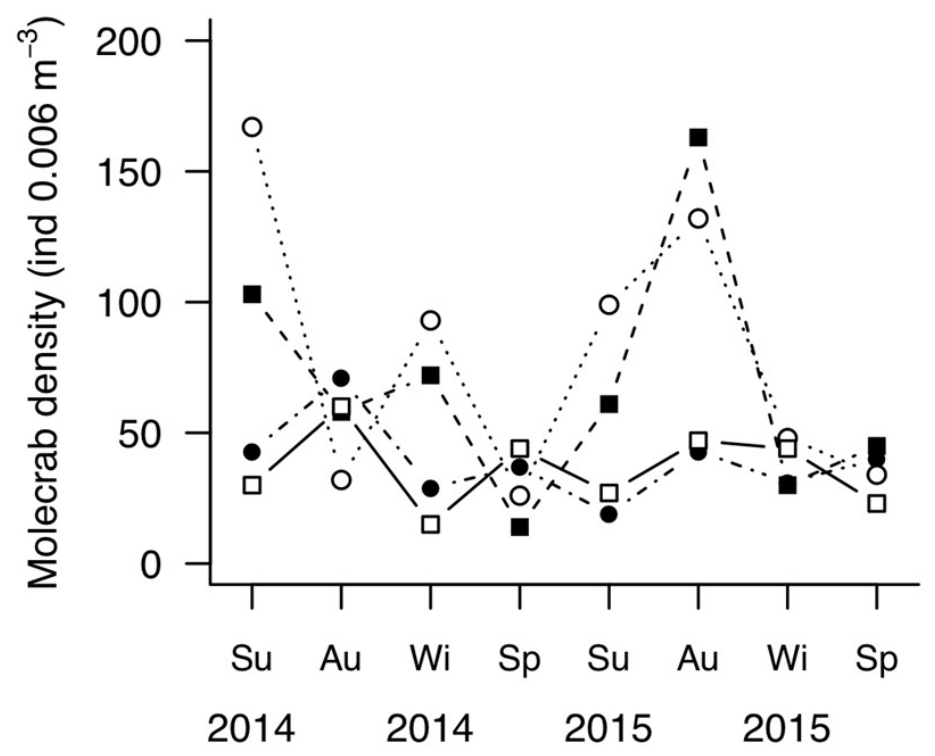

549

550 Figure 3: Rodríguez \& Valdivia. 
A

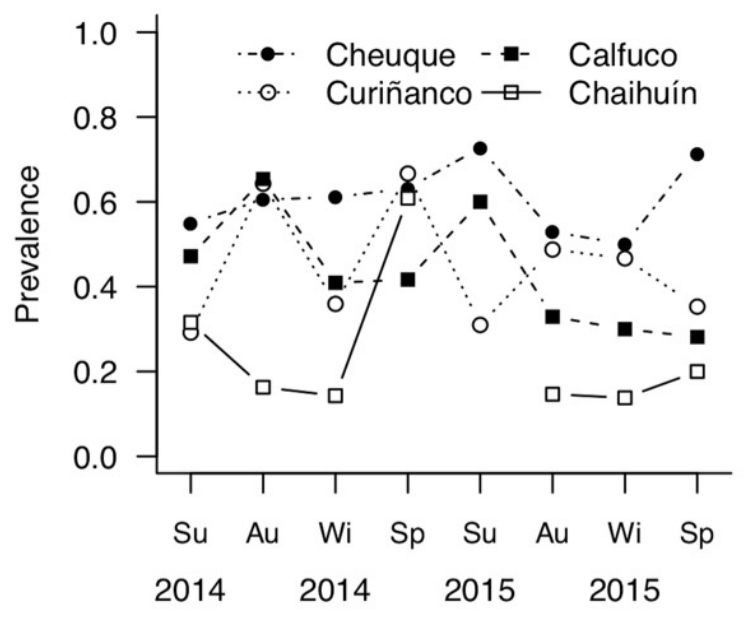

C

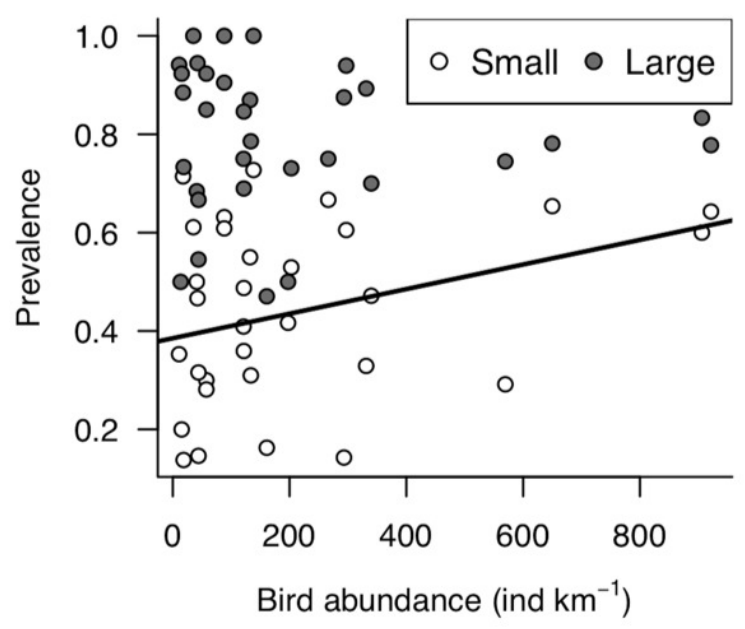

552

553 Figure 4: Rodríguez \& Valdivia.
B

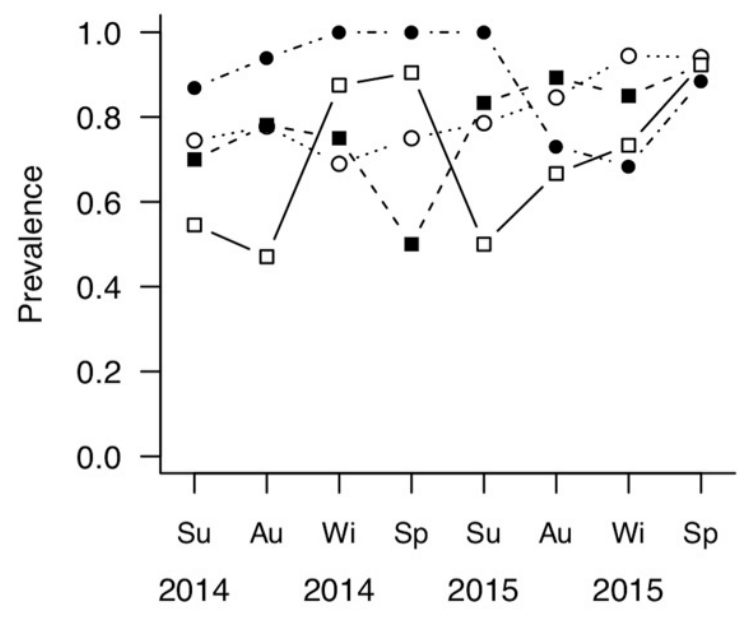




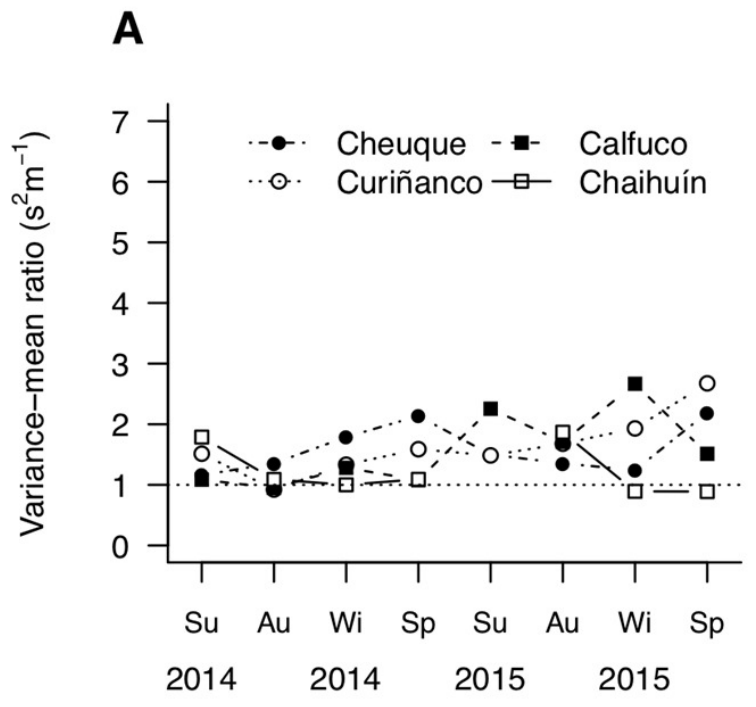

B

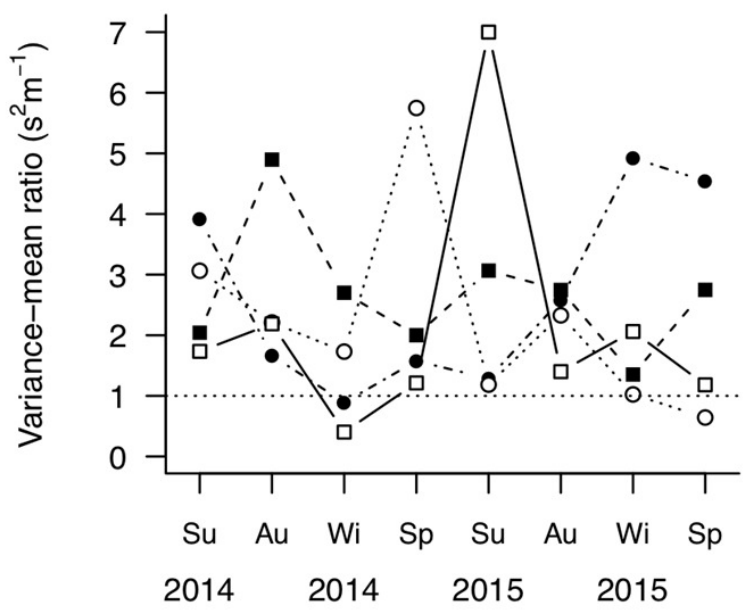

\section{C}

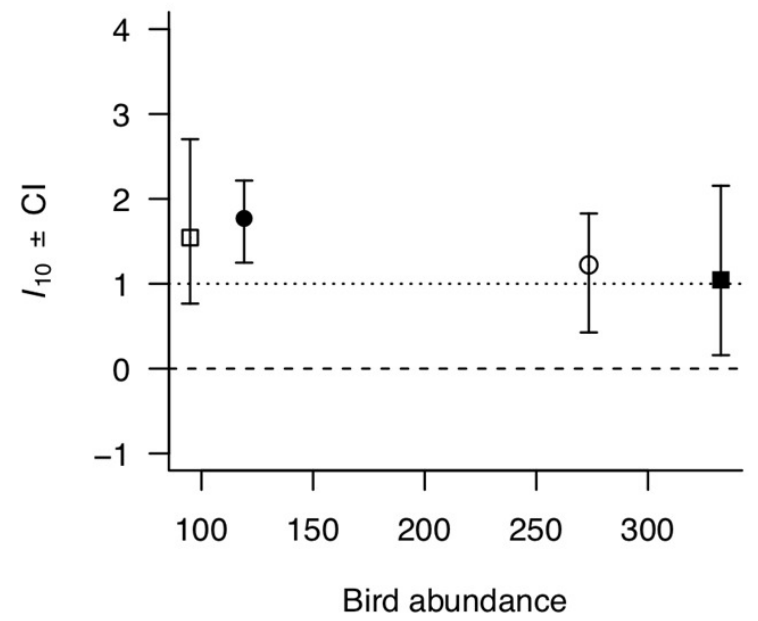

556

557 Figure 5: Rodríguez \& Valdivia

558 